\title{
ENERGY SECURITY OF GEORGIA AS A COMPILER OF GEO-ECONOMICS (HYDROPOWER CONTEXT)
}

\section{OTARI TUKVADZE}

\section{PhD Student}

Kutaisi University, Georgia

tukvadze.otari@gmail.com

\author{
ANA GUCHUA \\ PhD Student \\ Kutaisi University, Georgia \\ ana.guchua@gmail.com
}

\section{NIKOLOZ CHIKHLADZE}

Doctor of Economic Sciences, Doctor of Theology, Professor

Kutaisi University, Akaki Tsereteli State University,

Academician of the Georgian Academy of Economic Sciences, Georgia

nikoloz.chikhladze@unik.edu.ge

Abstract. The inevitable decline in the reserves of traditional energy sources is fostering interest in the development of renewable energy technologies around the world. The territorial characteristics and abundance of water resources in Georgia have great potential for the development of small hydropower, although the reality indicates a lack of high practical interest in this field. Comparative analysis of the characteristics of Georgian and foreign energy systems indicates the existence of a number of problems in the small hydropower industry in Georgia, which is related to the strategic understanding of the development prospects of this field at the state level. This situation naturally leads to an increase in investment risks. The aim of the article is to determine the conditions that will make the construction of small hydropower plants attractive and facilitate the formation of a relevant market through a geoeconomic understanding of the issue.

The object of research is the opportunities and tools to improve Georgia's energy security, taking into account the geoeconomic factor of the state. The subject of the research is to discuss some of the current problems related to Georgia's energy security in the geo-economic context, in the context of hydropower. Institutional analysis, synthesis and comparison methods are used in the processing of the article.

KEYWORDS: GEOECONOMICS, WATER RESOURCE, HYDROPOWER, ENERGY SECURITY.

For citation: Tukvadze, O., Guchua, A.,\&Chikhladze, N.,(2021). Energy Security Of Georgia As A Compiler of Geo-Economic (Hydropower Context). Globalization and Business. 12, 61-65. https://doi.org/10.35945/gb.2021.12.008

\section{INTRODUCTION}

Against the background of the growing energy crises in the world, the development of energy security strategies is becoming increasingly relevant for individual countries. Energy security is one of the key components of state security. The modern scientific literature focuses on the development of a new geo-economic concept, since knowledge of market factors alone can not guarantee success, and non-market factors also play an equally important role in achieving economic goals. Geoeconomic analysis, which combines various non-market factors, becomes much more relevant in this data.

The advantages of geo-economic analysis are due to the complex study of the geographical, historical, political, economic and institutional background of various issues. In this context, the geoeconomic approach is the most adequate analytical tool. Moreover, energy policy and energy security problems are a peculiar branch of geoeconomics issues.

Politically and economically, it is extremely important for the country to have at least one component of energy independence - electricity, which Georgia offers based on 
its water resources. It is a recoverable source of electricity. Compared to them, they are characterized by lower intensity impacts on the ecological equilibrium and it is possible to significantly mitigate these impacts by incurring additional costs.

The fact of the inevitable depletion of traditional energy sources in the world today puts on the agenda the need for the development of renewable energy technologies. Given the territorial characteristics and abundance of water resources, there is a great potential for the development of hydropower in Georgia, but the reality shows that no reforms have been implemented in this area that will bring practical results.

Taking into account the hydropower resources of Georgia, There is practically no comprehensive research and analysis on the geo-economic development opportunities of the country in the Georgian economic literature, on the basis of which a geo-economic understanding of Georgia's hydro resources should be made. The aim of the article is to study the potential and role of geo-economic opportunities of Georgia's hydro resources and to determine its impact on the economic development of the country in the process of integration of the modern world economy.

\section{GEORGIA'S HYDROPOWER CAPABILITIES}

Energy is the backbone of any country's economy and its proper functioning is of great importance. Along with the development of the economy in Georgia, energy consumption is also increasing - according to official statistics, the annual consumption of electricity is increasing by about $4.5 \%$. In recent years, a total of $800 \mathrm{MW}$ of capacity has been put into operation in Georgia, but this is not enough. Georgia has become an electricity importer from a net exporter. Continuation of this trend will hinder the further development of the country's economy. Georgia is not rich in hydrocarbons. Thus, it is not only expedient for us, but also vital for us to make optimal use of hydro resources. Especially since Georgia is rich in its hydro resources and the first place among natural resources is occupied by hydropower resources. In terms of water resources, Georgia is one of the richest countries in Europe, with 14,000 m3 of fresh surface water per capita, while the European average is only 9,300 m3 on average. According to official data, our technically feasible hydro resource is 90 billion kilowatt-hours per year, and economically justified - 50 billion kilowatt-hours, We have used only $20-22 \%$ of this indicator (MESD, 2018).

Despite the fact that Georgia is one of the first countries in the world in terms of water energy per unit area, its level of use significantly lags behind the developed countries abroad. Only $22 \%$ of hydro resources are exploited at the moment, while this figure even exceeds $90-95 \%$ in some European countries (Shvangiradze, 2021).

Every country with a growing economy is characterized by an increase in electricity consumption. Georgia's economy slightly but still was growing, except for 2020, therefore, electricity consumption is growing in Georgia. Generation sources in the country do not meet the growing demand and Georgia imports electricity every year. 2020 was no exception in this regard: Although, due to the pandemic, total electricity consumption was reduced, the country was still unable to independently generate the required energy and imports of electricity from neighboring countries became necessary.

Experts note that the construction of large hydropower plants causes flooding of large areas. Large amounts of agricultural lands and forests are flooded, Negatively affects the microclimate, increases humidity, changes the landscape, impedes the movement of river sediment and etc. There is also an increased risk of landslides. This background further intensifies the negative attitude of the population. In addition, the connection of remote users to a single electrical network resulted in transmitter losses. The experience of China and many other countries shows that the solution to this problem can be achieved with a reasonable combination of small and large hydropower plants (Jiang at al., 2015).

Today in Georgia, according to the The Electricity System Commercial Operator (ESCO), there are a total of 75 small power plants with a total capacity of $279.93 \mathrm{MW}$. (ESCO, 2020). For comparison: in China, which is the world's largest hydroelectric power producer, there are more than 47,000 plants that generate more than $25 \%$ of the total hydropower, and mainly small hydropower plants are used, which expands their geographical distribution and sales. Chinese companies are also actively pursuing innovations and patents from other countries (CREO, 2017). According to 2021 data, China still remains the world leader in terms of total hydropower capacity (more than $370 \mathrm{GW}$ ). For comparison, this figure in other countries looks like this: Brazil - 109 GW, USA 102 - GW, Canada - 82 GW, India - 50 GW, Japan and Russia lag behind India (49.91 and $49.86 \mathrm{GW}$ ), followed by Norway - $33 \mathrm{GW}$ and Turkey - 31 Gegawatt (Hydropower Status Report, 2021).

Solving the problem caused by drastic seasonal changes and effectively exploiting the potential of Georgia's rivers is possible through the construction of various types of hydropower plants, where the impact on natural river regimes will be minimal and the coexistence of natural and artificial systems will be improved.

The main document defining the energy sector of Georgia was adopted by the Parliament of Georgia in 2006. According to the "Main Directions of the State Policy in Energy Sector of Georgia", the most important long-term task is to "fully meet the demand for electricity in the country with its own hydro resources: gradually, first by import, and then - by replacing thermal generation." The Government of Georgia continues to support the so-called traditional energy projects (large hydro and thermal power plants) and does not make sufficient efforts to start new capacities of small hydropower plants. Analysis of more than 300 rivers in Georgia has shown that it is possible to build 1,200 small-scale diversion type hydropower plants, of which 700 could be built in western Georgia. The total installed capacity of these HPPs can be 3,000 MW, of which 2,000 MW will be supplied to Western Georgia; Annual output - 16,000 megawatt hours $(11,000$ megawatt hours in western Georgia) (OECD, 2006).

The main advantage of small hydropower plants is 
environmental safety and interest in them is caused by the following factors:

- Construction of small hydropower plants does not damage forests and agricultural lands, does not cause demolition of settlements and displacement of population (Which is extremely important considering the national and traditional values of Georgia. A clear example of this is a number of protests related to the construction of large hydropower plants);

- Small hydropower plants do not change the landscape and the environment in general, neither during the construction process nor during the operation phase;

- Water flowing through a small hydroturbine retains its original natural properties (Deepak, \& Katoch, 2015).

The state issues a license for the construction of hydropower plants in Georgia. In addition, most of the land is owned by the state and, consequently, the investor negotiates with the state, during which the opinion of the local population is less or in most cases not taken into account, which leads to a sense of protest and insecurity among the population. In addition to the fact that the state has a complete failure in communication, the processes are not transparent, the population does not have confidence in how fairly the permit for the construction of hydropower plants was issued. There are also doubts about the lack of qualified conclusions, which makes people even more negative about the construction of hydropower plants. All this, in the end, is reflected in the not so attractive investment environment of the country.

Georgia has an energy development strategy for 20172025 , according to which, in addition to hydropower plants of strategic importance, the construction of other small and medium hydropower plants is also envisaged. There is currently no proven mechanism to stimulate its development. Also, there is no well-designed regulatory framework under which private farms could generate electricity on small hydropower plants.

We should also emphasize the scientific and technical problems of small hydropower development in Georgia. If we compare small energy efficiency with large-scale energy, we can say that with the increase of energy, investment costs decrease significantly. Specific investments in hydropower plants with a capacity of more than $10 \mathrm{MW}$ are $20 \%$ lower per $\mathrm{kW}$ than in small hydropower plants (up to $1 \mathrm{MW}$ ). However, such calculations cannot be considered completely objective. The high unit costs of small hydropower plants are related to the cost of equipment, which accounts for about $60 \%$ of all costs. There is no serial production of such equipment in Georgia.

There are two options for the efficient use of small hydropower plants in Georgia. The first implies their connection to one power system, the second envisages autonomous use. Both options have significant advantages and disadvantages. Since all output power is designed for a certain optimum load, unavoidable deviations reduce equipment efficiency and lead to increased wear. If the power system is centralized, then the region can provide excess energy or receive additional power.
Power consumption in the local region always has very strong fluctuations, which means that the autonomous system without additional means of energy storage, the possibility of immediate shutdown of some turbine units or other means of maneuvering will work inefficiently. Power supply by a group of independent power plants will always have less reliability than an interconnected system (Wang et al., 2015).

Discussion of the issue shows that the development of small hydropower in Georgia depends on various economic, political, regulatory and social factors. Until the adoption of the state program for small-scale energy development, all development forecasts will be subjective. Naturally, in conditions of uncertainty we can not expect an increase in investment in small hydropower plants and equipment production.

\section{GEOECONOMIC UNDERSTANDING OF GEORGIA'S "HYDRO ENERGY EFFECTIVENESS"}

In the era of modern geoeconomics, various strategic resources have become important tools for geo-economic competition. Studies in the field of geoeconomics show the evolutionary characteristics of geo-economic relations between countries, reveal geo-economic competition and cooperation, which in turn laid the foundation for the development of geo-economic policy. However, in these studies we will rarely encounter issues of competitiveness between countries or the analysis of what makes some countries more competitive compared to other countries. Some authors argue that geopolitical competition paves the way for geoeconomic competition and places resources and markets at the center of competition between countries (Luttwak, 1993). In order to establish a favorable position in the world market, countries try to become competitive, gain economic advantage, for which the geo-economic situation of a particular economic entity is essential, which, in turn, implies the location of goods, services, capital and basic communications (Kvinikadze, 2017).

In modern conditions, geoeconomists study the socalled spatial agricultural processes and the impact of space on the factors of production and flows of goods / services. If economic geography studies the distribution of productive forces, in geoeconomics the spatial factor implies the influence of geographical location on the distribution of different resources, the arrangement of regional and global production nodes and "hubs".

Against this background, the discussion of the country's hydropower issues in the geo-economic context ensures the achievement of the strategic goal of geo-economic activity. It aims to diversify the sources of raw materials and supplies and gain a global / regional advantage by developing economic policies Which gives the country a worthy place in economic development and the world economy, enable successful positioning in global or regional geographical space.

The issue of geo-economic competition with respect to Georgia is a reflection of the country's location and resource potential, which gives it a comparative advantage over other 
countries. One of them is water and water-related resources, which is the first among the natural resources of Georgia. Georgia is one of the first countries in the world in terms of hydropower potential (rivers, lakes, reservoirs, glaciers, groundwater, swamps), considering the total area of the country.

In order to make effective use of the huge potential of Georgia's hydropower development, the geo-economic approach to this issue offers us to present the country as the future center of renewable energy in the region. This requires the development of a geo-economic policy that is compatible with the objectives of Georgia's energy policy and aims to diversify supply sources (which is achieved by building small hydropower plants in the respective regions) and develop export potential by any means. The geoeconomic positioning of the country is a contributing factor to the implementation of such a policy.

As mentioned, the advantages of geoeconomic analysis are due to the complex study of the geographical, historical, political, economic and institutional background of various issues.

When analyzing the country's hydropower from a geographical point of view, it is important to emphasize that the South Caucasus is a region connecting the WestEast (Europe and Central Asia) and the North-South (Russian Federation and the Middle East) and Georgia occupies a key place in this region. The main comparative advantage for Georgia in the region is its geographical location. Georgia's geoeconomic role as an important connecting artery of West and East, North and South is becoming even more relevant and it is in the geoeconomic interests of a large countries such as the US, EU member states, Russia, Turkey, Iran and China. The economic interests of Armenia, Azerbaijan and Central Asia are also important to the country. Thus, its own geo-economic positioning has turned Georgia into a sphere of global interests.

Since the spatial factor in geoeconomics implies the influence of geographical location on the distribution of different resources, it is important to emphasize the role of rivers in Georgia among natural energy resources. Georgia is one of the leaders in Europe and even in the world in terms of hydropower resources. There are 26,060 rivers on the territory of Georgia, the total length of which is about 60 thousand $\mathrm{km}$. The total fresh water supply of Georgia, which consists of glaciers, lakes and reservoirs, is $96.5 \mathrm{~km} 3$. Out of the total number of rivers, up to 300 rivers are distinguished in terms of energy, with a total annual potential capacity equivalent to 15 thousand megawatts, and an average annual energy equivalent of 50 billion kWh. (MESD, 2018).

In political and historical terms, it is important to highlight the factors that make Georgia dependent on the import of energy resources from neighboring countries, which poses a direct threat to the country's international economic security, given, that in the event of strained relations with a neighboring country, it may turn its energy resources into a political lever against our state. Moreover, one of the energy suppliers of Georgia, the Russian Federation, has a long history of turning its own resources into a political tool, of which Georgia has been a participant for several times. Also, in terms of electricity exports and imports, Georgia is most dependent on the Russian market, which is not a very good fact due to our relations with Russia. Moreover, along with Turkey and Azerbaijan, Russia is also Georgia's importer of electricity. Clearly, import dependence increases risks in terms of energy security. Based on a number of political or economic experiences, it is impossible to consider Russia (which has been in a conflict relationship with our country for several decades) as a reliable partner, therefore, we may find ourselves without enough electricity when Russia decides to do so. In addition, as a result of the devalued national currency, the price of imported electricity has risen even more, which is obviously an additional burden on the economy.

Despite the many problems in this area, hydropower resources in Georgia provide great potential for the construction of small hydropower plants. Their largescale construction should begin across the country. Given the economic and institutional background, this can be achieved in almost all districts and their construction can be done at the expense of existing production potential, financial resources and private capital in this region. The electricity generated by small hydropower plants can meet the demand for vital facilities in these areas. Construction of small hydropower plants in Georgia should be carried out regularly and in a appropriate manner, Environmental and other technical requirements must be met. A broad analysis of the costs and benefits to the state needs to be developed in depth. Due to the specific construction processes of the HPPs, their construction should be entrusted by the state to a qualified, experienced and reliable construction company and ensure that the ongoing processes are supervised by a team of highly qualified professionals. When considering the construction or non-construction of hydropower plants, it is important to know the terms of the contract between the investor and the state and, therefore, analyze and substantiate to what extent will the construction of the HPP be beneficial or harmful for the country under the terms of the contract, in order to find the answer to the main question, whether the benefits from the construction of the HPP outweigh the losses caused by it. The construction of each such HPP will take 2-3 years and it will be an invaluable contribution to ensuring energy security. Georgia will always be able to sell the excess seasonal and peak electricity generated by hydropower plants to neighboring countries at favorable prices.

\section{CONCLUSION}

Energy and energetics is a key challenge for twenty-first century humanity. Energy has always played a major role in protecting the national interests of large countries, as well as in the implementation of strategic plans of a number of small countries. In modern conditions, energy is the backbone of any country's economy and, in the end, significantly contributes to the sustainable development of this or that country. 
Global warming, the main cause of which is the accumulation of unprecedented amounts of carbon dioxide in the atmosphere as a result of the intensive use of non-renewable energy sources (oil and other fossil fuels), is one of the biggest problems in the world today. That is why the interest in the development of renewable energy (including water resources) technologies and the efficient use of renewable energy sources is becoming increasingly important in the world.

Therefore, the introduction of energy efficient technologies, the practical implementation of energy saving measures and the efficient use of local energy resources are the driving force of economic development of any country and one of the main preconditions for ensuring energy security. Improving energy efficiency is especially important for Georgia, where, on the one hand, the import of energy resources is mainly from outside, and on the other hand, the efficiency of the final use of these resources is low.

Thus, for Georgia, which is fulfilling the tasks of its statebuilding, the current or perspective functioning of the energy sector is of great importance. Clearly, it can be said without exaggeration that the development of energy infrastructure is one of the main directions for our country. Based on the analysis of the natural conditions of Georgia and the currently explored energy resources, as well as taking into account a number of technical and economic factors, at this stage there is no alternative to the priority development of hydropower for the country. Unlike other energy sources (coal, oil, natural gas, etc.), hydropower is a renewable energy source, which makes it particularly valuable. Especially in the conditions when only a small part of Georgia's technical hydropower potential is currently exploited.
It is clear from the above analysis that only one fifth of the country's hydro resources are used in Georgia. As Georgia has great potential for the construction of hydropower plants, it is really important to invest in this area, which will reduce electricity imports and increase exports. In addition, it is better to focus on the construction of small hydropower plants in different regions, which, along with social problems, will reduce environmental damage, as well as the risk of natural disasters and the cost of electricity distribution over long distances.

Geoeconomic analysis of Georgia's hydro resources allows us to see that the geo-economic positioning of the country, which includes its geographical spread and opportunities, historical experience, political significance and economic opportunities, plays an important role in the country's energy efficiency.

The presented paper discusses the issues of strategic development of Georgian small hydropower in the geoeconomic context, from which we find that it is necessary to use water resources wisely, profitably and, most importantly, for the good of the country, which can turn us into our invaluable wealth. The geoeconomic approach ensures the development of an economic policy that enables the country to successfully position itself in economic development and a worthy place in the world economy, in a global or regional geographical space. By exploiting hydro resources, Georgia can ensure its own energy independence and enter export markets as well. Increasing the export potential of electricity literally means developing the energy sector, the economy and increasing the budget.

\section{REFERENCES:}

China Renewable Energy Outlook 2017 (CREO 2017). URL:https://www.dena.de/fileadmin/dena/Dokumente/Themen_und_ Projekte/Energiesysteme/CREO-2017-booklet-EN-20171014.pdf?fbclid=IwAR1AsuxPdDTWpIRHFE7M1BRzeBa9Hc7zS8H xoMa4DWPmmapWL9jVQSOYqzE

Debt-for-Environment Swap in Georgia: Potential Project Pipelines for the Expenditure Programme, part two. OECD, 2006. http://www.oecd.org/dataoecd/28/58/36203819.pdf

Deepak, K., \& Katoch, S.S. (2015). Sustainability Suspense of Small Hydropower Projects: A Study from Western Himalayan Region of India. Renewable Energy, 76, 220-233.

Hydropower Status Report (2021). The International Energy Agency (IEA). URL:https://www.hydropower.org/status-report

Jiang S.Y., Zeng H.P., \& Cao M.X. (2015). Effects of Hydropower Construction on Spatial-Temporal Change of Land Use and Landscape Pattern. A case study of Jing Hong, Yunnan, China // Proceedings of the 3rd International Conference on Advances in Energy and Environmental Science (Zhuhai), 1-7. URL:https://doi.org/10.2991/icaees-15.2015.20

Kvinikadze G. (2017). Fundamentals of Geoeconomics, Tbilisi. 25.

Luttwak, E.N. (1993) The Endangered American Dream: How to Stop the United States from Becoming a Third World Country and How to Win the Geo-Economic Struggle for Industrial Supremacy; Simon \& Schuster: New York, NY, USA.

Ministry of Economy and Sustainable Development of Georgia (MESD) (2018). URL: http://www.economy.ge/

Shvangiradze T. (2021). Why do we need energy independence? URL: https://forbes.ge/blogs/ratom-gvtchirdeba-energodamoukidebloba/

The Electricity System Commercial Operator (ESCO). URL: https://esco.ge/ka

Wang, J.-H., Tseng, S.-W., \& Zheng, H. (2015). The paradox of small hydropower: Local government and environmental governance in China. The Journal of Development Studies, 51, 1475-1487. https://doi.org/10.1080/00220388.2014.973860 